\title{
Development of Practical Finite Element Models for Collapse of Reinforced Concrete Structures and Experimental Validation
}

\author{
Mario Bermejo, ${ }^{1}$ Anastasio P. Santos, ${ }^{1}$ and José M. Goicolea ${ }^{2}$ \\ ${ }^{1}$ Department of Geological and Mining Engineering, Technical University of Madrid, Madrid, Spain \\ ${ }^{2}$ Department of Mechanics and Structures, Technical University of Madrid, Madrid, Spain \\ Correspondence should be addressed to Mario Bermejo; mario.bermejo@upm.es
}

Received 25 July 2017; Revised 13 October 2017; Accepted 21 November 2017; Published 14 December 2017

Academic Editor: Nawawi Chouw

Copyright (c) 2017 Mario Bermejo et al. This is an open access article distributed under the Creative Commons Attribution License, which permits unrestricted use, distribution, and reproduction in any medium, provided the original work is properly cited.

\begin{abstract}
This paper describes two practical methodologies for modeling the collapse of reinforced concrete structures. They are validated with a real scale test of a two-floor structure which loses a bearing column. The objective is to achieve accurate simulations of collapse phenomena with moderate computational cost. Explicit finite element models are used with Lagrangian meshes, modeling concrete, and steel in a segregated manner. The first model uses 3D continuum finite elements for concrete and beams for steel bars, connected for displacement compatibility using a penalty method. The second model uses structural finite elements, shells for concrete, and beams for steel, connected in common nodes with an eccentricity formulation. Both are capable of simulating correctly the global behavior of the structural collapse. The continuum finite element model is more accurate for interpreting local failure but has an excessive computational cost for a complete building. The structural finite element model proposed has a moderate computational cost, yields sufficiently accurate results, and as a result is the recommended methodology.
\end{abstract}

\section{Introduction}

In recent years a number of civil buildings have collapsed after losing one or several bearing elements, due to explosive or impact loads, from accidental events or terrorist attacks. These buildings are often made of reinforced concrete and the redistribution of loads when an element is removed had not been taken into account in their design.

The terrorist attack in Oklahoma City USA [1] on the Alfred P. Murrah Federal Building on April 19, 1995, is a wellknown example of these loads. The attack claimed 168 lives and injured more than 680 people. 2300 kilograms of ANFO explosive were used resulting in enormous damage in the building and the collapse of a large part of it. Another example is the attack on the Argentine Israelite Mutual Association building in Buenos Aires on July 18, 1994 [2]. In this attack 85 people were killed and hundreds were injured. 275 kilograms of ANFO were used in this attack. The blast totally destroyed the exposed load-bearing walls and led to progressive failure of the floor slabs and collapse of the building. In Spain, the parking of the Madrid-Barajas Airport was attacked on
December 30, 2006, when a van bomb exploded, killing two and injuring 52 people; 500 to 800 kilograms of an unknown kind of explosive were used, resulting in the demolition of the five-floor structure [3]. An explosion from an accidental event occurred on February, 2012, in Astrakhan, Russia, in the fourth floor of a building, whose ten floors collapsed causing ten deaths and twelve injuries. In all these cases the damage in the structure was not only by the direct effect of the explosions but also by the subsequent collapse due to the loss of bearing elements. The damage in the structure can be catastrophic, so it is convenient to develop a practical methodology that can evaluate this phenomenon.

Several studies have been carried out on the progressive collapse of civil structures in recent years [4-6]. Some of them analyze reduced parts of the structure with detailed finite element models [7], while others propose an analytic approach $[8,9]$. The most common technique used for large buildings is finite element models with a homogeneous material for reinforced concrete [10-12].

In this paper we develop, apply, and discuss two different types of finite element models for studying the collapse 
of reinforced concrete structures subject to blast loads. LS-DYNA code [13] is employed for dynamic computer simulation, with Lagrangian Finite Elements, explicit time integration, and considering concrete and steel in a segregated manner. The focus of this work is on the structural collapse phenomenon; a more detailed explanation of the consideration of blast loading effects may be found in [14].

The first model uses 3D continuum finite elements for concrete and beams for steel bars, connected for displacement compatibility using a penalty method. This model is very detailed but has a high computational cost. The second model uses structural finite elements, that is, shells for concrete and beams for steel, connected in common nodes with an eccentricity formulation to take account of the position of the reinforcement. This model is less detailed than the previous one; however it reproduces the main structural features of the collapse with much lower computational cost. Both models are compared with a real scale test in order to validate the employed techniques.

\section{Test Description}

A six-column and two-floor structure of reinforced concrete was constructed for this test. The objective was to analyze the behavior of the structure when the bottom half of one of the central columns in the lower floor was removed. The removal was performed by blast charges located inside the column, in perforations previously disposed in the construction phase. When the charge was exploded the structure lost static equilibrium in a matter of milliseconds, entering into dynamic motion. Figure 1 shows the structure before the blast. The characteristics are as follows:

(a) Columns:

(i) Dimensions: $35 \mathrm{~cm} \times 35 \mathrm{~cm} \times 300 \mathrm{~cm}$.

(ii) Longitudinal reinforcement: 9 ribbed bars of $\phi 12 \mathrm{~mm}$ diameter.

(iii) Shear reinforcement: $\phi 6 \mathrm{~mm}$ diameter bars every $15 \mathrm{~cm}$.

(iv) Concrete cover: $3.5 \mathrm{~cm}$.

(b) Slabs:

(i) Solid concrete, $22 \mathrm{~cm}$ thickness.

(ii) Dimensions of floor slabs: $1100 \mathrm{~cm} \times 1435 \mathrm{~cm} \times$ $22 \mathrm{~cm}$.

(iii) Longitudinal reinforcement, top and bottom layers: according to Table 1 and Figure 2.

(iv) Punching shear reinforcement: $\phi 8 \mathrm{~mm}$ diameter bars every $15 \mathrm{~cm}$ in a zone of $90 \mathrm{~cm} \times 90 \mathrm{~cm}$ centered in the columns.

(v) Concrete cover: $3.5 \mathrm{~cm}$.

The foundation of the structure was made with a reinforced concrete slab of $40 \mathrm{~cm}$ thickness. The materials employed in the construction were $25 \mathrm{MPa}$ concrete and $500 \mathrm{MPa}$ ribbed steel bars. The structure was loaded with

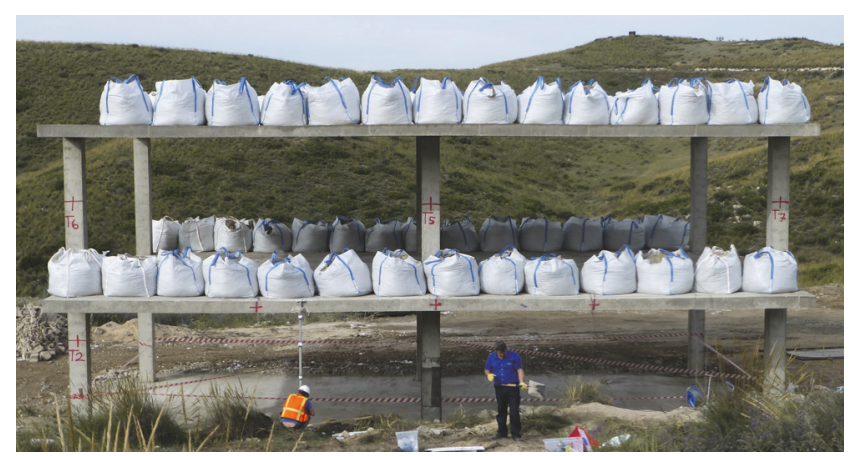

Figure 1: Photograph of the studied structure.

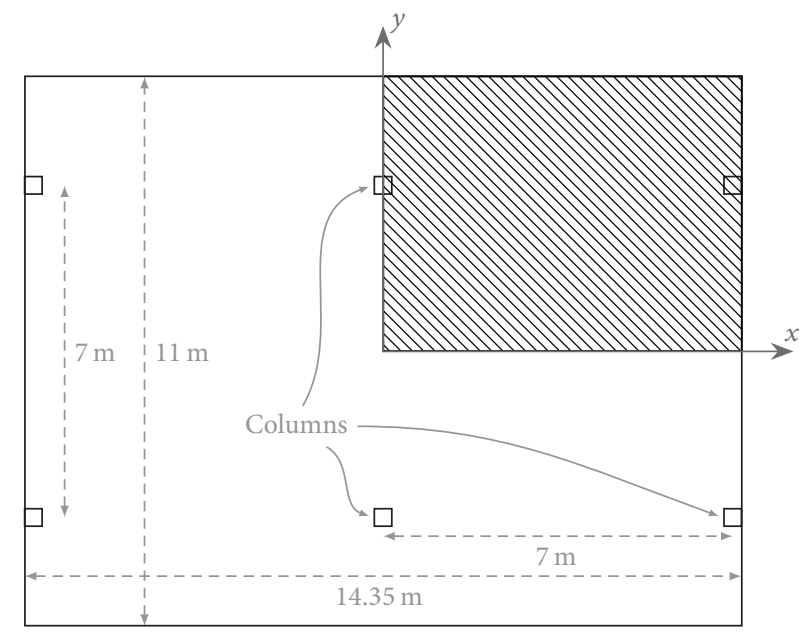

FIgure 2: Plan view of test structure, which is symmetric with respect to $x$ and $y$ axes. The reinforcement of the shadowed quarter is defined in Table 1.

sandbags in the overhangs, in an $200 \mathrm{~cm} \times 1435 \mathrm{~cm}$ area for each. The weight of sandbags was $7 \mathrm{kN} / \mathrm{m}^{2}$.

The process of collapse was recorded with a high-speed camera in the front of the removed column. A reel guide was $230 \mathrm{~cm}$ at the left of central column axis. In this guide two points were marked ( 1 and 2), with the $50 \mathrm{~cm}$ separation. The times when two points (A and B) of the first slab reach points 1 and 2 (Figure 3) were annotated and having measured the displacement an average velocity was obtained. The measured displacements and velocities are shown in the results Section 5.

\section{Continuum Finite Element Model}

In this model the geometry of the studied structure is reproduced accurately. The concrete is represented using continuum elements and the steel with beam type elements in a segregated manner. The two meshes are overlapped and the rebar to concrete connection is modeled via the Constrained Lagrange in Solid [15] feature in LS-DYNA, based on penalty constraints.

Eight node continuum elements with one Gauss point and hourglass control are used for concrete in the FE model. 
TABLE 1: Distribution of reinforcement in a quarter of a slab (Figure 2) of the test structure.

\begin{tabular}{|c|c|c|}
\hline Direction (see Figure 2) & Lines and separation & Length of reinforcement lines \\
\hline \multicolumn{3}{|c|}{ Top layer reinforcement } \\
\hline \multirow{9}{*}{$x$ direction } & 2 lines@14 cm & $\phi 10: x=0 \mathrm{~m}$ to $x=2.55 \mathrm{~m} ; \phi 8: x=4.50 \mathrm{~m}$ to $x=7.15 \mathrm{~m}$ \\
\hline & 5 lines@14 cm & $\phi 12: x=0 \mathrm{~m}$ to $x=2.55 \mathrm{~m} ; \phi 8: x=4.50 \mathrm{~m}$ to $x=7.15 \mathrm{~m}$ \\
\hline & 2 lines@14cm & $\phi 16: x=0 \mathrm{~m}$ to $x=2.55 \mathrm{~m} ; \phi 10: x=4.50 \mathrm{~m}$ to $x=7.15 \mathrm{~m}$ \\
\hline & 2 lines@14cm & $\phi 10: x=0 \mathrm{~m}$ to $x=2.55 \mathrm{~m} ; \phi 16: x=4.50 \mathrm{~m}$ to $x=7.15 \mathrm{~m}$ \\
\hline & 6 lines@14cm & $\phi 16: x=0 \mathrm{~m}$ to $x=2.55 \mathrm{~m} ; \phi 16: x=4.50 \mathrm{~m}$ to $x=7.15 \mathrm{~m}$ \\
\hline & 2 lines@14cm & $\phi 12: x=0 \mathrm{~m}$ to $x=2.55 \mathrm{~m} ; \phi 16: x=4.50 \mathrm{~m}$ to $x=7.15 \mathrm{~m}$ \\
\hline & 5 lines@14 cm & $\phi 12: x=0 \mathrm{~m}$ to $x=2.55 \mathrm{~m} ; \phi 8: x=4.50 \mathrm{~m}$ to $x=7.15 \mathrm{~m}$ \\
\hline & 5 lines@14 cm & $\phi 10: x=0 \mathrm{~m}$ to $x=2.55 \mathrm{~m} ; \phi 8: x=4.50 \mathrm{~m}$ to $x=7.15 \mathrm{~m}$ \\
\hline & 10 lines@14cm & $\phi 8: x=0 \mathrm{~m}$ to $x=2.55 \mathrm{~m} ; \phi 8: x=4.50 \mathrm{~m}$ to $x=7.15 \mathrm{~m}$ \\
\hline \multirow{6}{*}{$y$ direction } & 1 line @ $14.5 \mathrm{~cm}$ & $\phi 16: y=1.00 \mathrm{~m}$ to $y=5.47 \mathrm{~m}$ \\
\hline & 6 lines@14.5cm & $\phi 12: y=1.00 \mathrm{~m}$ to $y=5.47 \mathrm{~m}$ \\
\hline & 7 lines@14.5cm & $\phi 10: y=1.00 \mathrm{~m}$ to $y=5.47 \mathrm{~m}$ \\
\hline & 23 lines@14.5cm & $\phi 8: y=1.00 \mathrm{~m}$ to $y=5.47 \mathrm{~m}$ \\
\hline & 5 lines@14.5cm & $\phi 10: y=1.00 \mathrm{~m}$ to $y=5.47 \mathrm{~m}$ \\
\hline & 6 lines@14.5 cm & $\phi 12: y=1.00 \mathrm{~m}$ to $y=5.47 \mathrm{~m}$ \\
\hline \multicolumn{3}{|c|}{ Bottom layer reinforcement } \\
\hline \multirow{3}{*}{$x$ direction } & 10 lines@15 cm & $\phi 10: x=0.55 \mathrm{~m}$ to $x=7.15 \mathrm{~m}$ \\
\hline & 7 lines@12 cm & $\phi 10: x=0 \mathrm{~m}$ to $x=7.15 \mathrm{~m}$ \\
\hline & 20 lines@15 cm & $\phi 10: x=0.55 \mathrm{~m}$ to $x=7.15 \mathrm{~m}$ \\
\hline \multirow{2}{*}{$y$ direction } & 44 lines@15cm & $\phi 10: y=0 \mathrm{~m}$ to $y=3.10 \mathrm{~m} ; \phi 10: y=4.00 \mathrm{~m}$ to $y=5.47 \mathrm{~m}$ \\
\hline & 3 lines@15 cm & $\phi 10: y=0 \mathrm{~m}$ to $y=5.47 \mathrm{~m}$ \\
\hline
\end{tabular}

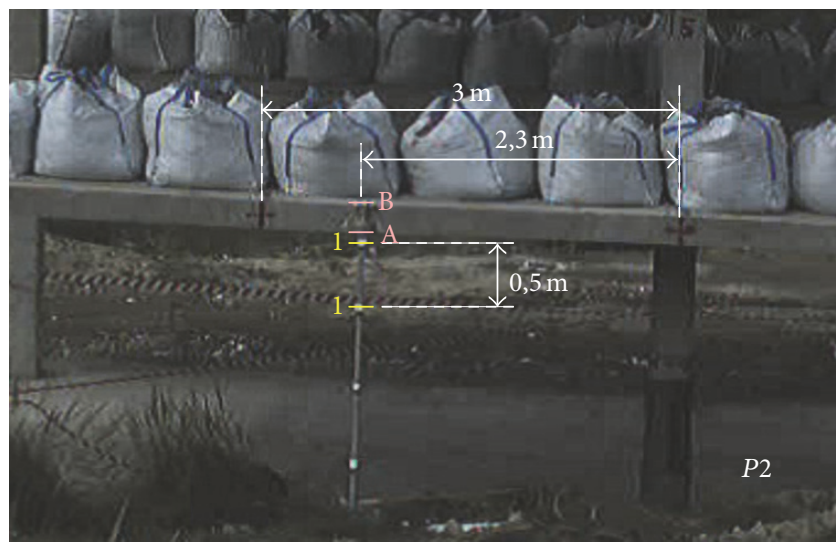

Figure 3: Picture of the points of measure in the slab. $P 2$ is the half of the column before it was removed.

An hourglass formulation with Flanagan-Belytschko stiffness form of artificial viscosity [16] is used to avoid zero energy modes of deformation in the underintegrated elements.

The mesh size is composed by $5 \mathrm{~cm} \times 5 \mathrm{~cm} \times 5.5 \mathrm{~cm}$ elements for the slabs and $5 \mathrm{~cm} \times 5 \mathrm{~cm} \times 5 \mathrm{~cm}$ elements for the columns. Every single bar of the steel reinforcement is reproduced with Hughes-Liu beam type elements using $2 \times 2$ Gauss points in the cross section and located in the exact position within the concrete mesh.

The concrete behavior is represented using the Continuous Surface Cap Model (CSCM) [17] material model
TABle 2: Parameters for CSCM material model for concrete.

\begin{tabular}{lc}
\hline Parameter & Value \\
\hline Mass density & $2300 \mathrm{~kg} / \mathrm{m}^{3}$ \\
Unconfined compression strength & $25 \mathrm{MPa}$ \\
Maximum aggregate size & $19 \mathrm{~mm}$ \\
Erode parameter & 1.05 \\
\hline
\end{tabular}

implemented in LS-DYNA. This material model is isotropic and has different response in tension and compression, three plasticity surfaces (TXE tensile, TOR shear, and TXC compression), softening in compression, damage in tension, and erosion formulation for elimination of material. Figure 4 shows the material response for unconfined uniaxial tension and compression. The damage formulation models both strain softening and modulus reduction $\left(\sigma_{i j}^{d}=(1-d) \sigma_{i j}^{v p}\right)$ where $d$ is a scalar damage parameter that transforms the stress tensor without damage $\left(\sigma_{v p}\right)$ into the stress tensor with damage $\left(\sigma^{d}\right)$. Damage initiates and accumulates when strain-based energy terms exceed the damage threshold for brittle damage $\left(\tau_{b}=\sqrt{E \varepsilon_{\max }^{2}}\right)$ and ductile damage $\left(\tau_{d}=\right.$ $\left.\sqrt{0.5 \cdot \sigma_{i j} \varepsilon_{i j}}\right)$. Elements are eroded when damage exceeds $d=$ 0.99 and the maximum principal strain exceeds an erosion parameter value. The CSCM material model [17] is defined by the basic parameters shown in Table 2 .

The steel behavior is represented using the Piecewise Linear Plasticity material model (Figure 5), which is an 


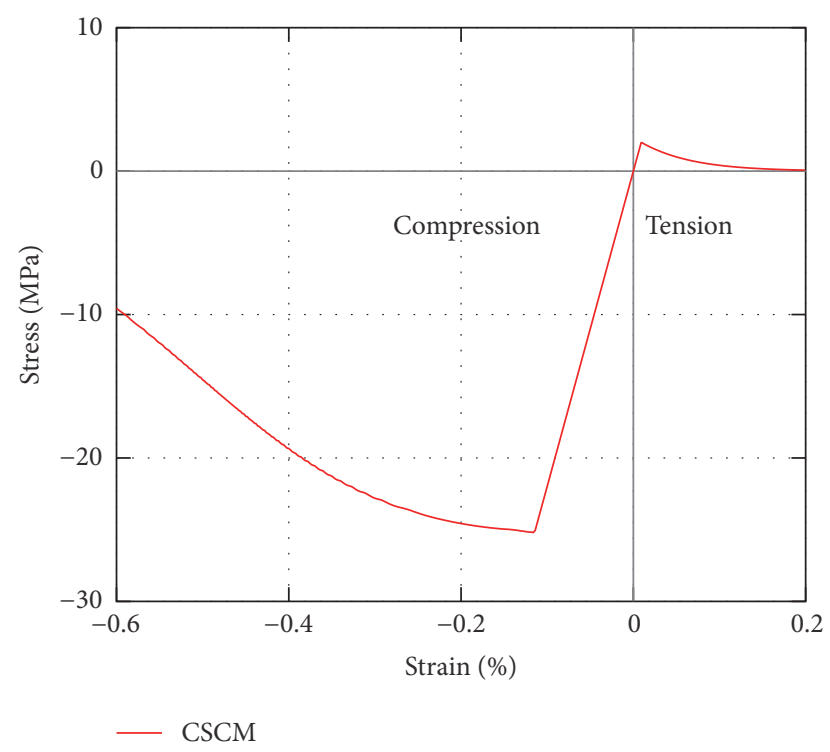

FIGURE 4: Stress-strain diagram for $25 \mathrm{MPa}$ CSCM material model. Unconfined uniaxial tension and compression.

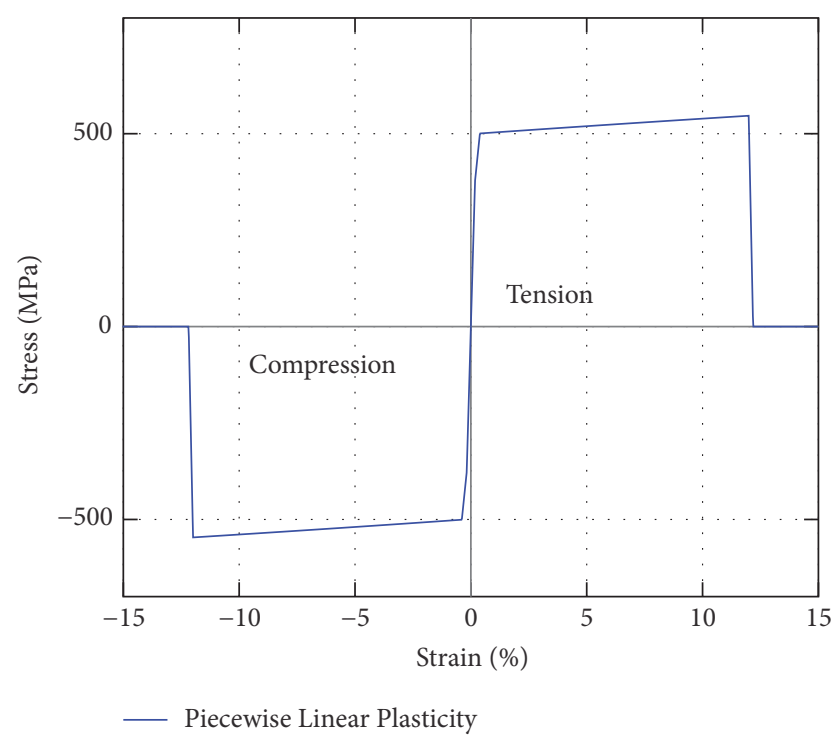

FIGURE 5: Stress-strain diagram for $500 \mathrm{MPa}$ yield stress Piecewise Linear Plasticity material model.

elastoplastic material model with hardening, equal response in tension and compression, and failure when effective plastic strain reaches the ultimate strain. The material parameters are shown in Table 3.

Although distinct meshes are employed for concrete and steel, using continuum and beam type elements, respectively, their degrees of freedom are coupled with kinematic constraints which achieve full deformation compatibility. This is performed using the option Constrained Lagrange in Solid within LS-DYNA.

The bases of the columns are fixed and the ground is modeled as a fixed rigid slab. A penalty formulation is used for the contact between different parts of the structure, which considers the collisions between columns, slabs, and the
TABle 3: Parameters for Piecewise Linear Plasticity material model for steel rebars.

\begin{tabular}{lc}
\hline Parameter & Value \\
\hline Mass density & $7850 \mathrm{~kg} / \mathrm{m}^{3}$ \\
Young's modulus & $210 \mathrm{GPa}$ \\
Poisson's ratio & 0.3 \\
Yield stress & $500 \mathrm{MPa}$ \\
Tangent modulus & $420 \mathrm{MPa}$ \\
Effective plastic strain to failure & 0.11 \\
\hline
\end{tabular}

ground. The loads applied on the structure are the gravity loads caused by the sandbags and the self-weight. The load of the sandbags in the overhangs is modeled as a vertical distributed weight of $7 \mathrm{kN} / \mathrm{m}^{2}(200 \times 1435 \mathrm{~cm}$ each $)$. The selfweight of the structure is modeled through prescribed gravity loading applied on the lumped nodal masses.

The initial state of equilibrium under the permanent loads is achieved through a dynamic relaxation step [18]. Next, the half column is eliminated, triggering the collapse process.

The LS-DYNA commands and nondefault used, respectively, for contact constraints, load of the sandbags, selfweight, and dynamic relaxation are Contact Automatic General (sstyp: 2, mstyp: 2); Load Segment Set (sidr: 2, $7000 \mathrm{~Pa}$ ); Load Body Z (sidr: 2, $9.8 \mathrm{~m} / \mathrm{s}^{2}$ ); Dynamic Relaxation (nrcyck: 250, drfctr: 0.9, drterm: 0.49, idrflg: -1)

The results obtained with this model are discussed in Section 5.

\section{Structural Finite Element Model}

In this model shell elements are used to represent the concrete and the steel is modeled with beam type elements in a segregated manner. The connection between the rebars and the shells is performed in the nodes with an offset formulation that takes into account the eccentricity of the reinforcement [19].

The concrete for the slabs and the columns is modeled with shell elements using two Gauss points through the thickness. The steel rebars are modeled with Hughes-Liu beam type elements using $2 \times 2$ Gauss points in the cross section. The individual rebars included in the model represent realistically the actual quantity of reinforcement in the structure.

For the columns $17.5 \mathrm{~cm} \times 15 \mathrm{~cm}$ shells are used forming a section with cross form, with the same mass and inertia as the real column section (Figure 6). This modeling scheme for the columns provides a correct representation of the stiffness and strength under bending and compression, including nonlinear response and collapse, and includes simultaneously an active surface on which the blast loads will act in the case of an explosion event.

The nine bars of the longitudinal reinforcement are modeled independently, located overlapped within the longitudinal column axis, and connected to the nodes of the column concrete shell elements with the appropriate geometrical offset.

The shear reinforcement is modeled also independently with $6 \mathrm{~mm}$ diameter bars, their nodes being connected with 


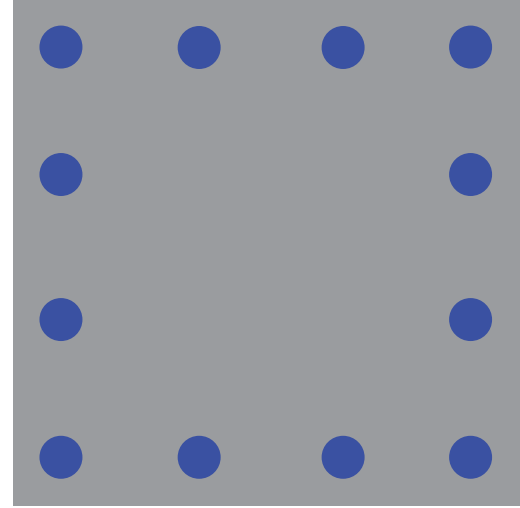

(a)

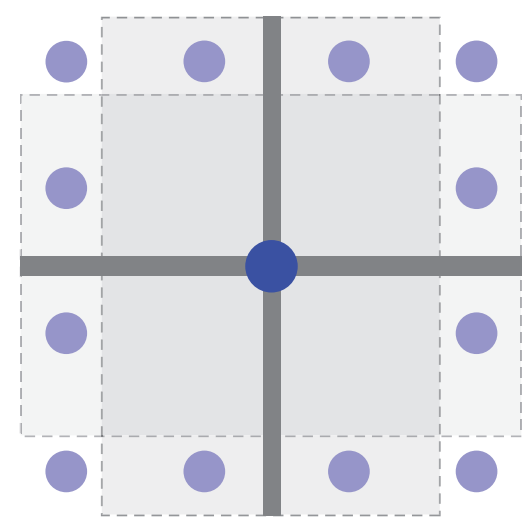

(b)

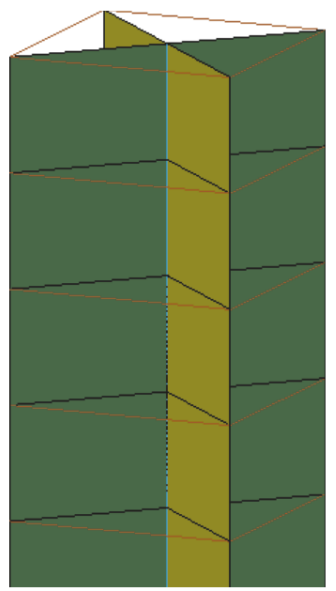

(c)

Figure 6: Column for structural finite element model: (a) real geometry of column section, (b) sketch of crossed shells, each with its corresponding virtual thickness, and with nine longitudinal bars overlapped at the column axis and their virtual position with geometrical offset, and (c) detail of model mesh.

the concrete shells at the nodes farther away from the column axis. Figure 6 shows the real section and the equivalent section formed by cross shells and offset reinforcement.

The slabs are modeled with flat shell elements of $20 \mathrm{~cm} \times$ $20 \mathrm{~cm}$ size. The distribution of reinforcement in the slabs distinguishes between support zone, central zone, top and
TABLE 4: Parameters for EC2 material model and Mat Add Erosion formulation for concrete.

\begin{tabular}{lc}
\hline Parameters for EC2 material model & Value \\
\hline Mass density & $2300 \mathrm{~kg} / \mathrm{m}^{3}$ \\
Unconfined compression strength & $25 \mathrm{MPa}$ \\
Tensile stress to cause cracking & $2.5 \mathrm{MPa}$ \\
Tension stiffening & $1.2 \mathrm{GPa}$ \\
\hline Parameters for Mat Add Erosion & Value \\
\hline Minimum principal strain at failure & -0.032 \\
Maximum principal strain at failure & 0.025 \\
\hline
\end{tabular}

bottom layers, and the two perpendicular directions $(x, y)$ in the slab, following the coordinates in Figure 2:

(i) Top layer, equivalent bars:

(a) $x$ direction, with $20 \mathrm{~cm}$ of separation: 14 lines of $\phi 15.7, x=0 \mathrm{~m}$ to $x=2.60 \mathrm{~m}$ and $x=4.60 \mathrm{~m}$ to $x=7.20 \mathrm{~m} ; 13$ lines of $\phi 10.9, x=0 \mathrm{~m}$ to $x=2.60 \mathrm{~m}$ and $x=4.60 \mathrm{~m}$ to $x=7.20 \mathrm{~m}$.

(b) $y$ direction, with $20 \mathrm{~cm}$ of separation: 10 lines of $\phi 13.4, y=1.10 \mathrm{~m}$ to $y=5.50 \mathrm{~m} ; 17$ lines of $\phi 9.4, y=1.10 \mathrm{~m}$ to $y=5.50 \mathrm{~m} ; 8$ lines of $\phi 13.4$, $y=1.10 \mathrm{~m}$ to $y=5.50 \mathrm{~m}$.

(ii) Bottom layer, equivalent bars:

(a) there is no distinction between central and support zones.

(b) $x$ direction, with $20 \mathrm{~cm}$ of separation: 27 lines of $\phi 11.5, x=0 \mathrm{~m}$ to $x=7.20 \mathrm{~m}$.

(c) $y$ direction, with $20 \mathrm{~cm}$ of separation: 35 lines of $\phi 11.6, y=0 \mathrm{~m}$ to $y=5.50 \mathrm{~m}$.

Additionally, the shells of the slabs near the columns, in an $80 \mathrm{~cm} \times 80 \mathrm{~cm}$ area $(4 \times 4$ shells), are modeled with $4 \%$ of transverse reinforcement to take account of punching shear reinforcement.

The concrete is modeled using the Eurocode 2 (EC2) [20] material model implemented in LS-DYNA. This material model is isotropic, with different response in tension and compression, softening in compression, damage in tension, hardening, and failure.

The steel reinforcement can be included homogenized with the concrete. This option is only used for the shear reinforcement of the slabs. This material model does not include by itself erosion, but this capability may be added with Mat Add Erosion formulation. Figure 7 shows the material response for unconfined uniaxial displacement. The parameters used for erosion were previously calibrated [14, 21] for the mesh size used in order to obtain equivalent erosion in both finite element models.

The material parameters used are shown in Table 4 .

The boundary conditions, contact constraints, and loads are identical to the continuum model: columns fixed in their base, the ground as rigid slab, contact between different parts of the structure, and gravity loads for the sandbags and selfweight.

The response of the model is discussed in the next section. 


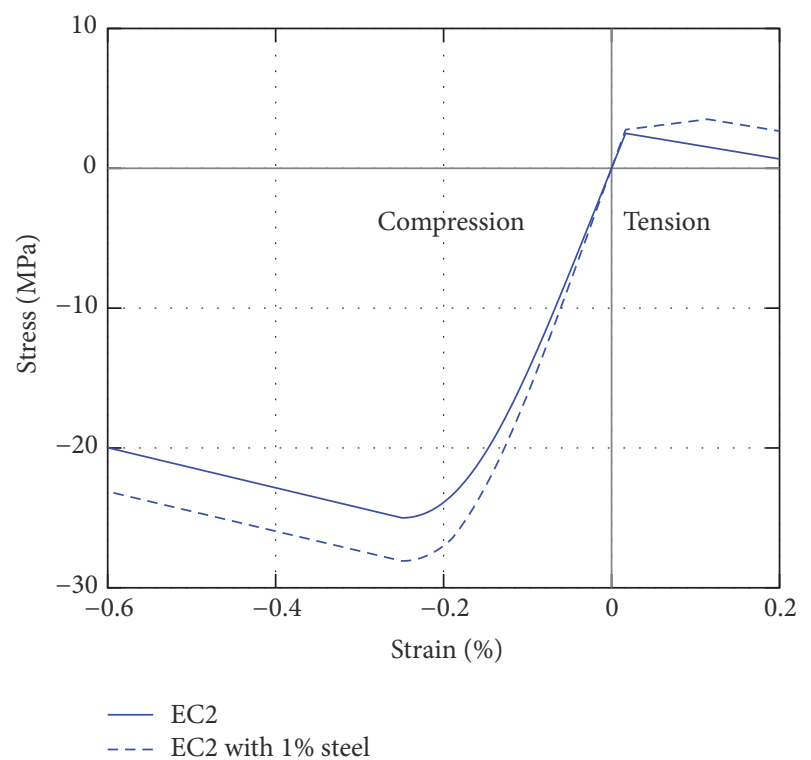

Figure 7: Stress-strain diagram for $25 \mathrm{MPa}$ EC2 material model. Unconfined uniaxial tension and compression. Material model without homogeneous steel reinforcement and with $1 \%$ of steel reinforcement.

\section{Results and Discussion}

5.1. Test Results. Discrete measurements were performed for material points A and B (Figure 3), as follows:

(i) Point A: position 1 at $0.16 \mathrm{~s}$, position 2 at $0.54 \mathrm{~s}$.

(ii) Point B: position 1 at $0.33 \mathrm{~s}$, position 2 at $0.71 \mathrm{~s}$.

Measuring the position of these two points an average velocity of $1.3 \mathrm{~m} / \mathrm{s}$ for both is obtained. Unfortunately the accelerometers that were located on the structure failed, so the displacement is the only reliable measure. The cloud of dust caused by the blast prevented reliable measures beyond one second from the collapse initiation.

5.2. Comparison between Test and Models. Figures 8 and 9 show the comparison between the measured displacements and velocities and the calculated ones for both the continuum and structural finite element models. The difference between points $A$ and $B$ in the calculated models is negligible and only one curve for both points A and B is drawn. Consequently, the four displacements measured in the test can be represented in one figure.

Figure 8 shows a good correlation between the four measured displacements and the displacement histories of the finite element models.

In Figure 9 the velocity histories of the continuum finite element model and the structural finite element model are compared with the measured average velocity, resulting in a good agreement between average values.

Figures 10, 11, and 12 show the evolution of the structural collapse, comparing the pictures obtained from the slow motion video with the meshes of the models at corresponding times.

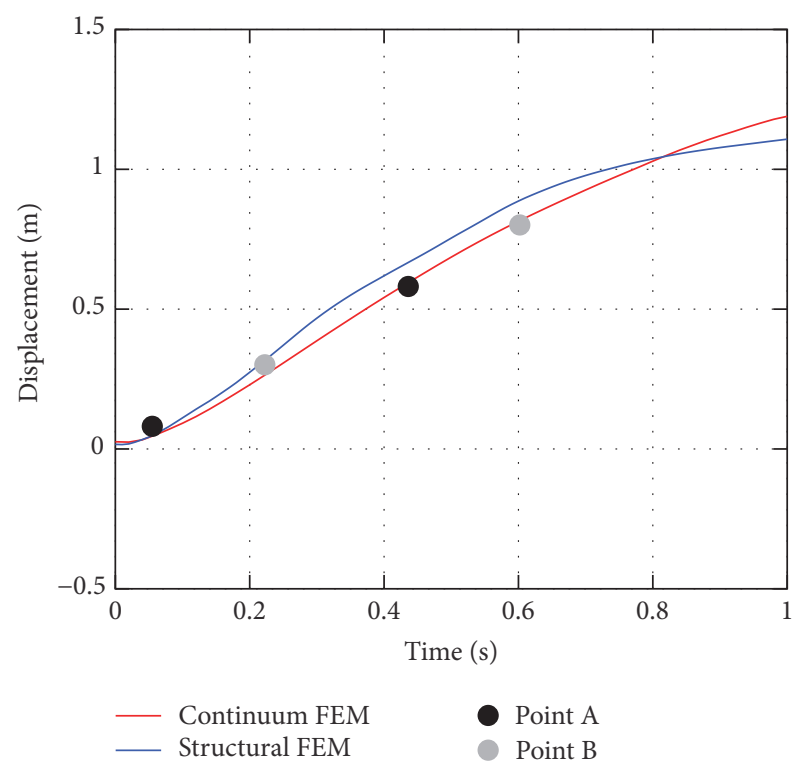

FIGURE 8: Comparison of displacements between finite element models and test.

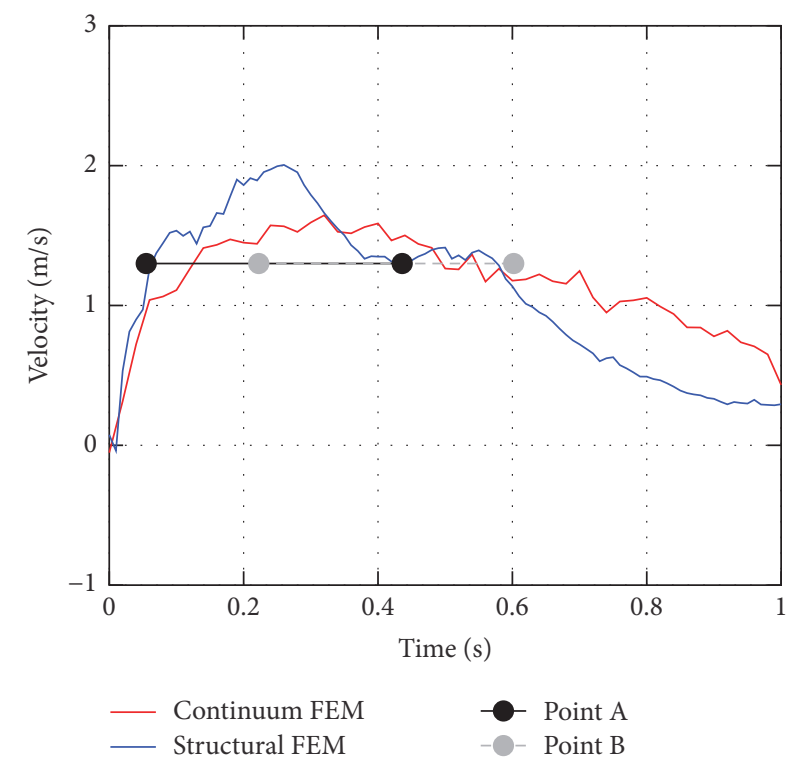

FIGURE 9: Comparison of velocities between finite element models and test.

In the first figure, at time $0.6 \mathrm{~s}$, the slabs of the two floors show a large displacement because of the loss of support of the removed column. Despite these large displacements only cracking in the concrete is obtained and the reinforcement is still capable of maintaining the integrity of the slabs. The columns also maintain their structural integrity. In the second figure, at time $1.1 \mathrm{~s}$, the displacements have increased in the zone of the removed column; the unions between the slabs and the columns acquire large rotations and begin to fail. However, the velocity is still low due to the contribution of the rest of the structure, and the columns keep their integrity. In the third figure, at time $2.6 \mathrm{~s}$, the central column located in 

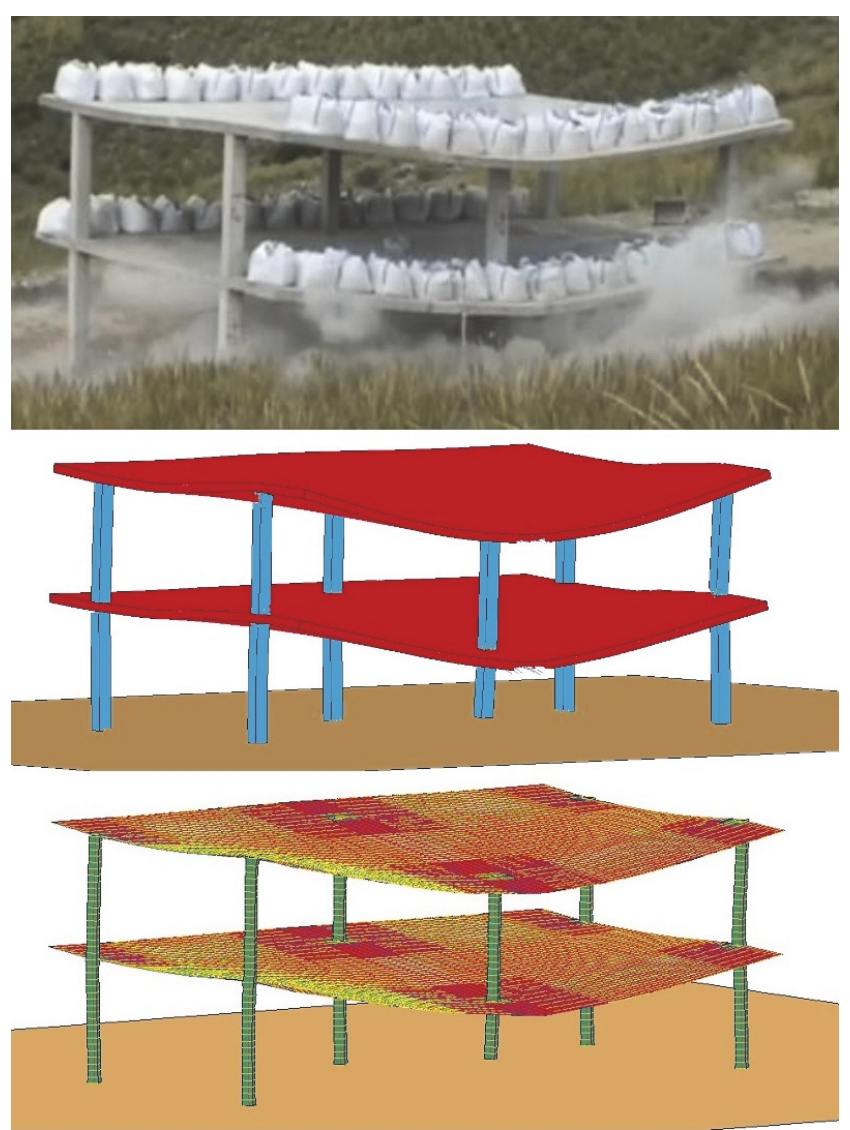

FIGURE 10: Comparison between test, continuum model, and structural model at $0.6 \mathrm{~s}$ after column removal.

the back and in the bottom fails due to the additional load it must support, and the complete structure collapses. Several unions between slabs and columns fail completely and the slabs fall independently of the columns. The type of collapse is the failure of concrete and reinforcement of the slabs in the center of the structure. As may be observed in the figures, the global behavior of the structure is adequately represented.

5.3. Discussion. The models used for the reinforced concrete structure have proven their capacity to reproduce the complete process of the progressive collapse. The continuum finite element model is the most accurate model, with more precision in the displacement and velocity and better prediction of concrete failure, especially in the zone where the columns support the slabs. The structural finite element model is slightly less accurate than the continuum finite element model in terms of displacement and velocity. The local failures are not represented in detail, but it has enough precision to reproduce accurately the global collapse phenomenon. The great advantage of structural finite element model is a much smaller computational cost. Table 5 shows the comparison between both models in terms of number of elements, calculation time, and memory. The structural finite element model is much more efficient.

Bearing in mind a realistic model for a complete building would be of much greater size and computational cost, for
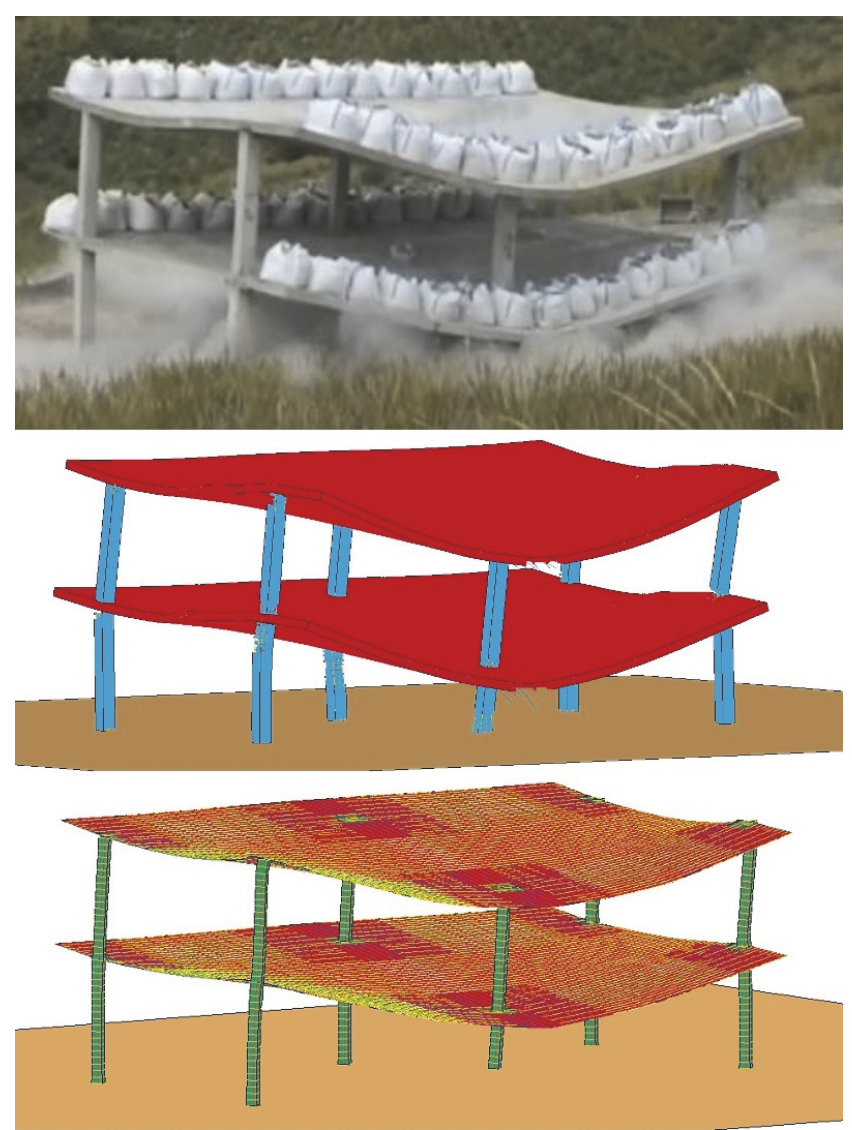

FIGURE 11: Comparison between test, continuum model, and structural model at $1.1 \mathrm{~s}$ after column removal.

the continuum finite element model the computer resources required render it difficult to afford. On the contrary, the structural finite element model can be used with moderate computational cost.

The same conclusion may be reached for analysis of blast loads on concrete buildings [14] and its subsequent collapse.

\section{Conclusions}

This paper discusses the modeling of reinforced concrete structures collapse with explicit finite element models. Two different methodologies are proposed. The finite element code LS-DYNA is used in the analysis.

The first type of model uses continuum elements for concrete and beam elements for reinforcement in a segregated way. The connection between rebars and concrete is modeled using a penalty formulation (Constrained Lagrange in Solid). CSCM and Piecewise Linear Plasticity material models are used for concrete and steel, respectively. Damage formulation and erosion parameters are shown in Section 3. Contact constraints, load of the sandbags, self-weight, and dynamic relaxation formulations are modeled with Contact Automatic General, Load Segment Set, Load Body Z, and dynamic relaxation commands of LS-DYNA.

The second type of model uses shell elements for concrete and beam elements for reinforcement in a segregated way. The 
TABLE 5: Computational cost comparison between continuum FE model and structural FE model for four parallel processors Intel(R) Core(TM) i7-2600 CPU @ 3.40 GHz.

\begin{tabular}{lcc}
\hline & Number of elements & \\
\hline $\begin{array}{l}\text { Continuum FE model } \\
\text { Structural FE model }\end{array}$ & 540,000 continuum elements and 67,000 beams \\
& Calculation time & 9800 shells and 14,600 beams \\
\hline Continuum FE model & Memory (in LS-DYNA words) & 23 min \\
Structural FE model & and $24 \mathrm{~s}$ \\
\hline & & $192,000,000$ \\
\hline Continuum FE model & $7,500,000$ \\
\hline
\end{tabular}
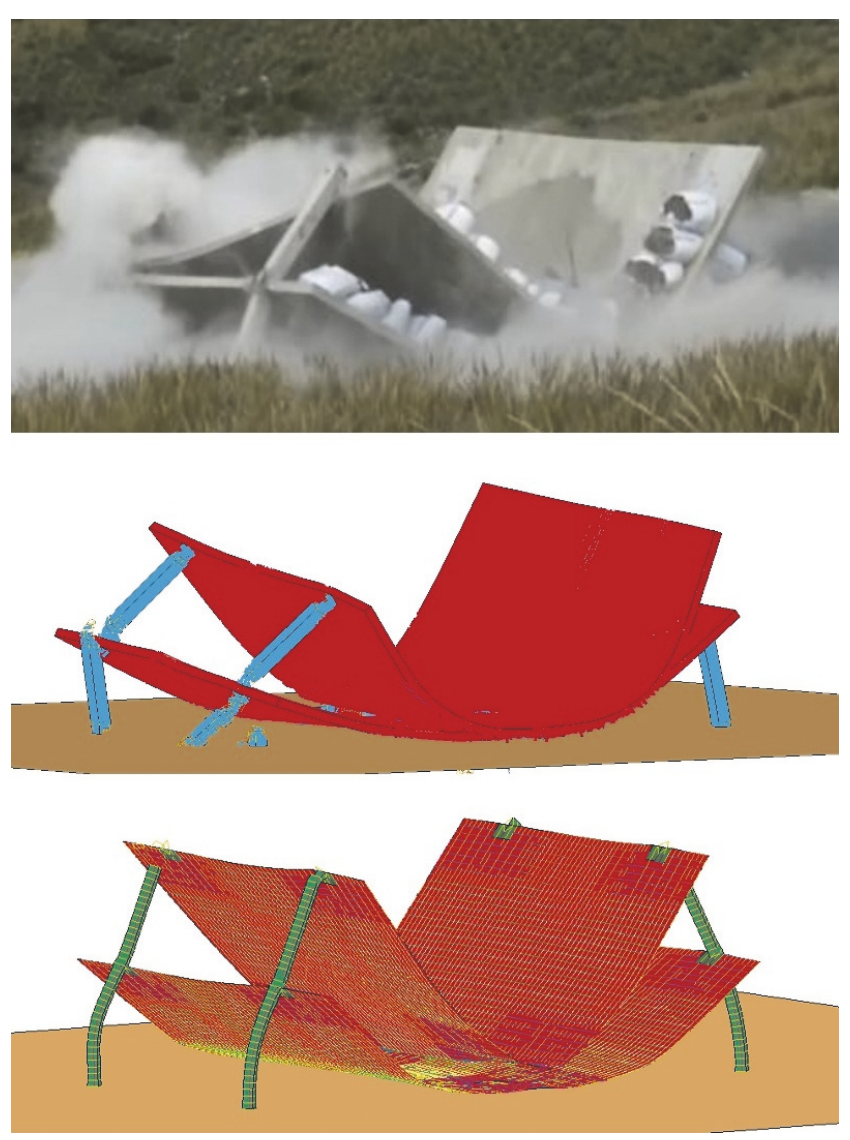

FIGURE 12: Comparison between test, continuum model, and structural model at $2.6 \mathrm{~s}$ after column removal.

connection between rebars and concrete is modeled using common nodes of the meshes. EC2 and Piecewise Linear Plasticity material models are used for concrete and steel, respectively. Contact constraints, load of the sandbags, selfweight, and dynamic relaxation formulations are identical to the continuum model.

The modeling techniques have been validated through the comparison with a real scale test of a two-floor structure. The numerical values for model parameters are shown in Sections 3 and 4.
Based on the results presented in this paper, the following conclusions are drawn:

(i) The methodologies used in the two proposed finite element models have enough precision to reproduce the global collapse phenomenon in an accurate way.

(ii) The continuum finite element model has a high precision in displacements and velocities, and in the prediction of local failures of the concrete. The structural finite element model has enough precision with lower computational cost than the continuum element model and can be used with advantage for simulation of a large frame-type building.

(iii) For modeling the collapse of full buildings, structural finite element models with concrete shells including segregated steel beam elements coupled using common nodes are recommended.

\section{Conflicts of Interest}

The authors declare that there are no conflicts of interest regarding the publication of this paper.

\section{Acknowledgments}

This study was carried out with the support of SEGTRANS project (Investigación, Desarrollo y Demostración de Innovadores Sistemas de Mejora de la Seguridad Integral en Terminales de Transporte), financed by Centre for the Development of Industrial Technology of Spain (CDTI), and the experiment was realized in the Technological Institute $L a$ Marañosa belonging to Department of Defense of Spain.

\section{References}

[1] P. F. Mlakar Sr., W. G. Corley, M. A. Sozen, and C. H. Thornton, "The Oklahoma City bombing: analysis of blast damage to the Murrah Building," Journal of Performance of Constructed Facilities, vol. 12, no. 3, pp. 113-119, 1998.

[2] B. M. Luccioni, D. Ambrosini, and R. Danesi, "Colapso estructural bajo cargas explosivas," Mecánica Computacional, vol. XXII, pp. 957-970, 2003.

[3] H. Corres and E. Romero, "Reconstrucción módulo D aparcamiento Madrid Barajas T-4," in Resúmenes del IV Congreso de 
Asociación científico-técnica del hormigón estructural (ACHE), 2008.

[4] J. E. Crawford, "Retrofit methods to mitigate progressive collapse," in The Multihazard Mitigation Council of the National Institute of Building Sciences, Report on the July 2002 National Workshop and Recommendations for Future Effort, 2002.

[5] U. Starossek, "Typology of progressive collapse," Engineering Structures, vol. 29, no. 9, pp. 2302-2307, 2007.

[6] R. Ahmadi, O. Rashidian, R. Abbasnia, F. Mohajeri Nav, and N. Usefi, "Experimental and numerical evaluation of progressive collapse behavior in scaled rc beam-column subassemblage," Shock and Vibration, vol. 2016, Article ID 3748435, 17 pages, 2016.

[7] T. Krauthammer, R. L. Hall, S. C. Woodson, J. T. Baylot, J. R. Hayes, and Y. Sohn, "Development of progressive collapse analysis procedure and condition assessment for structures," Defense Technical Information Center, 2002.

[8] G. Kaewkulchai and E. B. Williamson, "Beam element formulation and solution procedure for dynamic progressive collapse analysis," Computers \& Structures, vol. 82, no. 7-8, pp. 639-651, 2004.

[9] Y. Shi, Z.-X. Li, and H. Hao, "A new method for progressive collapse analysis of RC frames under blast loading," Engineering Structures, vol. 32, no. 6, pp. 1691-1703, 2010.

[10] B. M. Luccioni, R. D. Ambrosini, and R. F. Danesi, "Analysis of building collapse under blast loads," Engineering Structures, vol. 26, no. 1, pp. 63-71, 2004.

[11] F. Fu, "Progressive collapse analysis of high-rise building with 3-D finite element modeling method," Journal of Constructional Steel Research, vol. 65, no. 6, pp. 1269-1278, 2009.

[12] L. Kwasniewski, "Nonlinear dynamic simulations of progressive collapse for a multistory building," Engineering Structures, vol. 32, no. 5, pp. 1223-1235, 2010.

[13] J. O. Hallquist, LS-Dyna, Theory manual, 2006.

[14] M. Bermejo, P. Anastasio, and J. M. Goicolea, "A methodology to calibrate structural finite element models for reinforced concrete structures subject to blast loads," in Proceedings of the 9th International Conference on Structural Dynamics, 2014.

[15] A. Abu-Odeh, "Modeling and simulation of bogie impacts on concrete bridge rails using ls-dyna," in Proceedings of the 10th international LS-DYNA Users Conference, Livermore Software Technology Corporations, pp. 8-10, 2008.

[16] D. Kosloff and G. A. Frazier, "Treatment of hourglass patterns in low order finite element codes," Numerical and Analytical Methods in Geomechanics, vol. 2, no. 1, pp. 57-72, 1978.

[17] Y. D. Murray, A. Abu-Odeh, and R. Bligh, Evaluation of LSDYNA Concrete Material Model, vol. 159, 2007.

[18] A. S. Day, "An introduction to dynamic relaxation (dynamic relaxation method for structural analysis, using computer to calculate internal forces following development from initially unloaded state)," The Engineer, vol. 219, pp. 218-221, 1965.

[19] M. Bermejo, J. M. Goicolea, F. Gabaldón, and A. Santos, "Impact and explosive loads on concrete buildings using shell and beam type elements," in Proceedings of the 3rd International Conference on Computational Methods in Structural Dynamics and Earthquake Engineering (COMPDYN '11), May 2011.

[20] J. O. Hallquist et al., LS-DYNA Keyword User's Manual, Livermore Software Technology Corporation, 2013.

[21] M. Bermejo, A. P. Santos, J. M. Goicolea, and A. Pérez, "Evaluación de acciones explosivas sobre estructuras de hormigón armado mediante elementos finitos," Informes de la Construcción, vol. 67, no. 539, p. e095, 2015. 


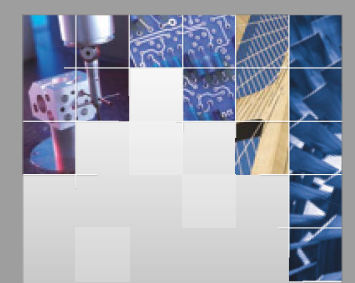

\section{Enfincering}
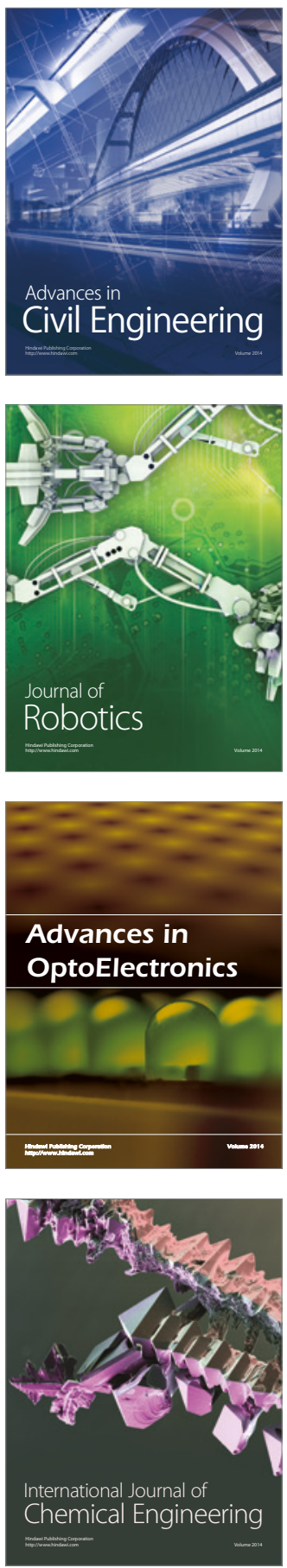

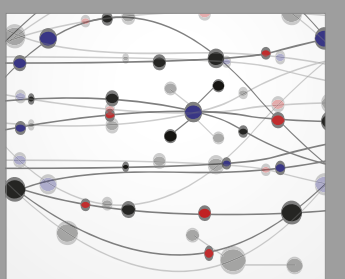

The Scientific World Journal

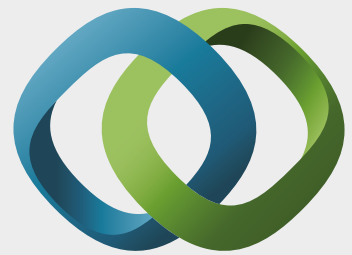

\section{Hindawi}

Submit your manuscripts at

https://www.hindawi.com
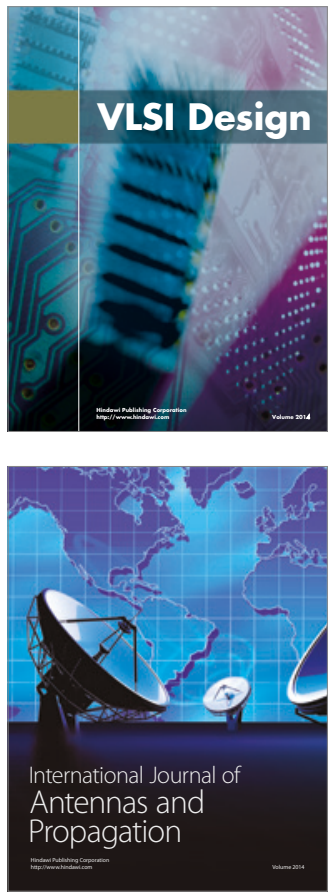

\section{Rotating}

Machinery
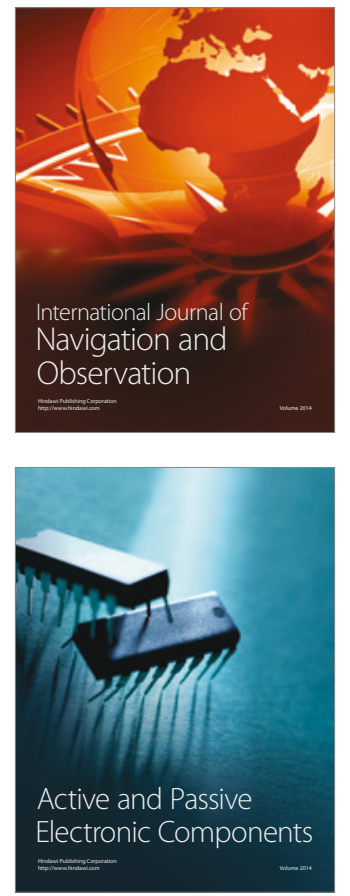
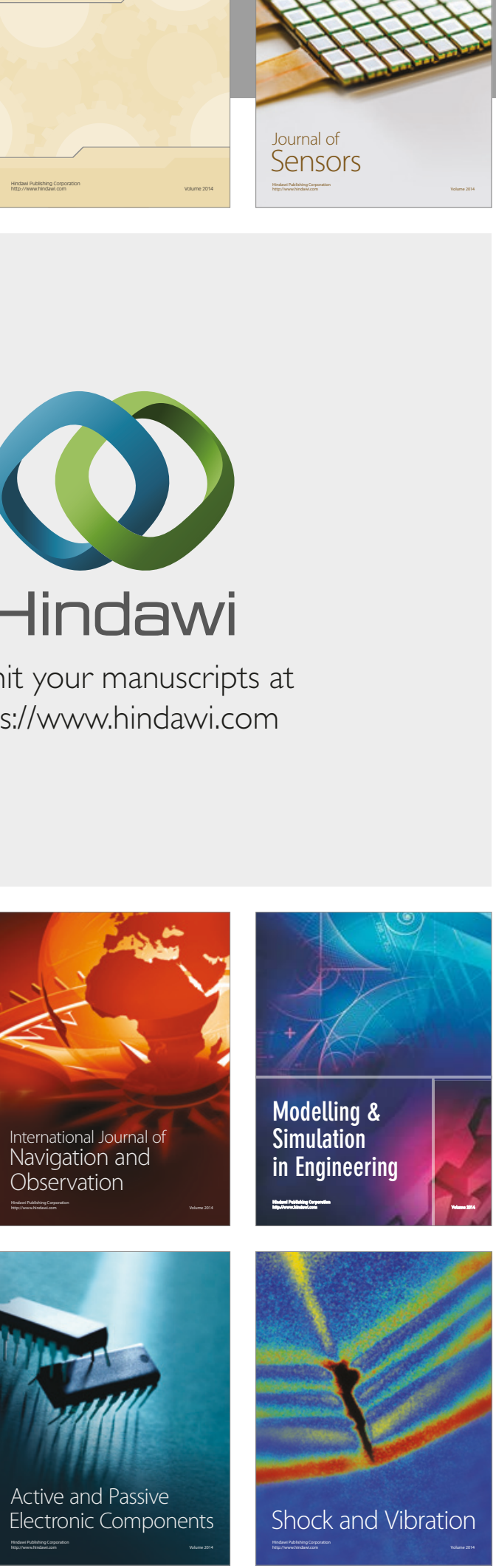
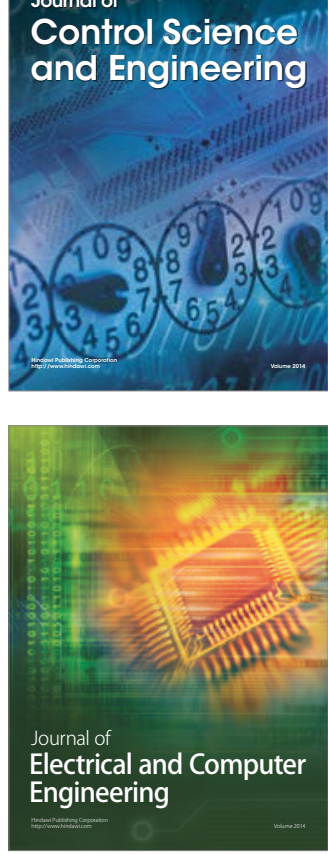

Distributed

Journal of

Control Science

and Engineering
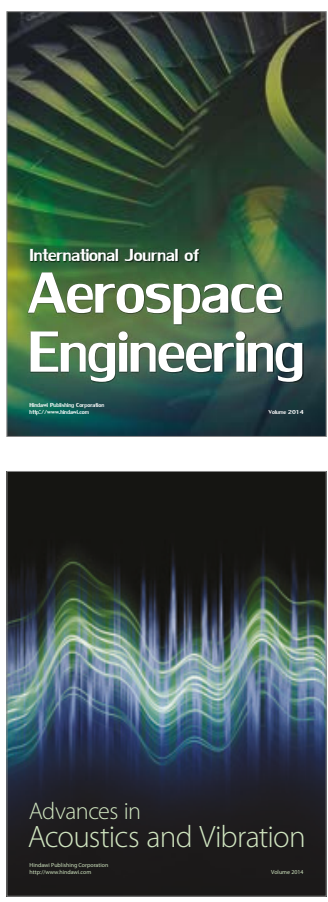

Sensor Networks 